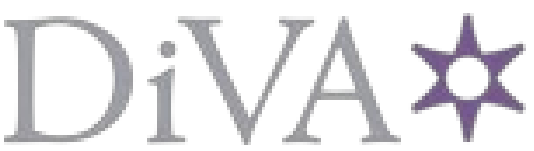

http://www.diva-portal.org

This is the accepted version of a text published by $S A G E$.

Forsler, I. (2018).

Researching infrastructural imaginaries in education through future workshops. SAGE Research Methods Cases. doi:10.4135/9781526442116

N.B. When citing this work, cite the original published paper.

Permanent link to this version:

http://urn.kb.se/resolve?urn=urn:nbn:se:sh:diva-33951 


\title{
Researching Infrastructural Imaginaries in Education Through Future Workshops
}

\section{Ingrid Forsler}

Södertörn University, Sweden

\section{Discipline}

Communication and Media Studies [D13]

\section{Academic Level \\ Intermediate Undergraduate \\ Contributor Biography}

Ingrid Forsler is a PhD candidate in Media and Communication Studies at Södertörn University in Stockholm, Sweden. She has a background in art and media education and her PhD project examines the relationship between technology and visual art education.

\begin{abstract}
This case describes the development and implementation of the Future workshops method, as part of a mixed methodology in a $\mathrm{PhD}$ project about media technologies and future imaginaries in school art education. The workshop method described here is an attempt to visualize media infrastructures in teaching and the imaginaries surrounding them, thereby making them possible for the research participants to discuss and critique. The practical lessons learned from this case are that designing a functioning research workshop resembles the pedagogic planning done in teaching. Ritual aspects and emotional labor are highlighted as necessary in the process, as well as staying sensitive to the context where the workshops are performed, and to my role as a researcher in this context. Discussing some of the shortcomings of creative methods, the study concludes that workshop methods benefit from being combined with other methods to include, for example, historical perspectives in the analysis. The messiness and non-linearity of the
\end{abstract}


research process is described in the text as a simultaneous development of research questions, theoretical concepts, experiences, and methods.

\section{Learning Outcomes}

By the end of this case, students should be able to

- Identify key challenges of researching media infrastructures

- Identify key challenges of researching social imaginaries

- Discuss the possibilities and limits of visual and participatory methodologies in social science or humanities research

- Develop and apply a creative workshop design to a chosen field of study

\section{Case Study}

\section{Project Overview and Context}

This case study presents creative workshops as a research method, developed to capture the social imaginaries, or shared norms and ideas about the aim of education, surrounding the use of media technologies in the art classroom, for school administration and for professional development. These technologies, when put to use, are part of structuring everyday practice as well as the way we think about teaching and learning, and are conceptualized in the study as media infrastructures of art education. The workshop approach is informed by participatory and creative approaches from human geography, social development, and critical infrastructure studies. The more specific future workshops methodology used here was developed by Robert Jungk and Norbert Müllert (1987) to create citizen participation in decision-making processes.

The workshops were carried out with art teacher students in Sweden and Estonia, as part of my ongoing $\mathrm{PhD}$. The aim of the project is to understand how social imaginaries about media infrastructures is played out in school art education, or more concretely, how the school subject has changed in relation to new media technologies, and how this is negotiated in the art teacher community. Early on in the research process, the idea was to study this through an ethnographic approach consisting of participation in online forums for art teachers, observation, and in-depth interviews with art teachers. However, after performing some pilot interviews and doing a first 
mapping of the online landscape of art education, this approach seemed to direct the study too much towards pedagogy and everyday struggles concerning working conditions, rather than towards social imaginaries and material conditions.

Recognizing this, I abandoned the ethnographic approach for a mixed methodology consisting of semi-structured interviews; teachers and instructors showing online and offline spaces for education and professional development; and the student workshops described here. This mixed approach is inspired by Lisa Parks's (2015, p. 355) critical methodology for a humanist study of infrastructures, combining site visits with experimental and participatory approaches in an attempt to inform "ways of thinking about what infrastructures are, where they are located, who controls them, and what they do." Compared to the more open ethnographical approach, this methodological package made it possible for me to direct the participants towards specific topics of relevance to my research.

One important step in deciding on and developing a renewed set of methods was then to recognize the relation between material environments and the organization of education as media infrastructures. This perspective brought a body of literature and concepts, valuable not only for methodological considerations but also for framing the subject and formulating research questions. Critical media infrastructure studies, the study of distribution systems supporting the contemporary media landscape, is an upcoming field of study within media and communication studies. Studies in this area often depart from Susan Leigh Star and Karen Ruhleder's (1996, p. 113) well-cited definition of infrastructures as far-reaching, embedded systems often built upon other technologies and infrastructures. Star and Ruhleder also show that the embedment of infrastructures in everyday practice and discourse makes the concept essentially relational. A thing is never an infrastructure in itself, but becomes an infrastructure in relation to organized practices, such as professional work. Because infrastructures are embedded in everyday practice, they often remain invisible, or at least opaque, as long as they are functioning, as put by Geoffery Bowker and Susan Leigh Star (1999, p. 33):

Information infrastructure is a tricky thing to analyse. Good, usable systems disappear almost by definition. The easier they are too use, the harder they are to see. 
Although built into the material environment and sometimes clearly visible, the mundanity of infrastructures can prevent us from paying attention to them. However, infrastructures are not invisible at all times. A power failure at work makes us recognize the importance of infrastructure supporting such systems as electric light, Internet, and electronic locking systems. Infrastructures are also visible in the moment of formation, before they have faded in to the background and merged with daily routines.

The imaginaries surrounding media technologies and infrastructure also risk fading into the background. Taken-for-granted norms about a good society or desired future are seldom articulated in everyday speech, but nevertheless, as shown by Sheila Jasanoff and Sang-Hyun Kim (2009), guide work practice, policy, and modes of organization. Taking schools as an example, we can assume that they are organized around some idea about what knowledge and competences children and young people will need in the future, but exactly how this future looks or even what we would want it to look like, is rarely defined. This became evident for me during the pilot interviews I did with Estonian art teacher educators, where questions about the aim of school art education, or how they imagined art education 20 years from now, caused confusion and some degree of irritation among the participating teacher educators.

This left me with two opaque systems: the infrastructures embedded in everyday practice and the tacit understandings surrounding them. But how do you study something neither you as a researcher or the research participants can really see? The response from the Estonian teacher educators taught me that just asking wouldn't work. To discuss invisible structures with the participants, I had to find a way to make these structures appear. I decided to do this through a workshop, combining visualizations of the perceived infrastructures with visualizations of social imaginaries about the role of school art education.

\section{Research Practicalities}

Designing a workshop means offering a limited set of material resources for expression — in this case colored paper, pens, glue, and scissors - as well as suggesting a theme for discussion, namely the media technologies that structure art education. This approach is of course very different from the original ethnographic approach, whereby the researcher is participating in 
events but not directing them. However, for the infrastructures that make up our lived environment to be pulled out of the background, some kind of intervention was necessary. This intervention has two aims: to inform my research and to facilitate discussion among the participants about the material and symbolic conditions of their practice. This aligns with media scholar Lisa Parks's (2009, n.p.) suggestion, that it is our duty as citizens to be aware of the infrastructural systems that surround us and for media researchers to develop "ways of visualizing and developing literacy about infrastructures and the relations that take shape through and around them."

In critical infrastructure studies, this is often done through what Bowker and Star (1999) call infrastructural inversion. This means focusing on the mundane and habitual parts of material and symbolic culture, such as how the size of a painting is dependent on the format of canvas rolls or the width of the museum doorposts. In human geography, there is a similar interest in mapping the mundane. In 1960, Kevin Lynch used cognitive maps, hand-drawn by the participants, to explore how individuals perceive their local neighborhood or hometown. But human geography has also been occupied with visualizing unfamiliar inaccessible places, like foreign countries or outer space.

Building on this dynamic between the familiar (acquaintance with the school subject and professional practice) and the unfamiliar (concealed infrastructures and future social imaginaries), the workshop appropriated the cognitive mapping method by letting participants draw images of technologies that make up art education, and then collectively organize these images into a cognitive map. Although resembling practices for reaching the subconscious, such as art therapy or children psychology, it is important to point out that this kind of drawing-based study, as David Gauntlett (2007) calls it, is as context dependent and socially constructed as other methods. However, the slowness of the drawing process might give the participants time to reflect and develop their stories. The drawing also results in artifacts that can be put on a table and moved around, making it easier for the participants to remember what has been said, to nuance statements and to facilitate discussion in the group.

\section{Research Design and Implementation}


The process of planning the workshop design, finding and inviting student participants in two countries (Sweden and Estonia), conducting the workshops and interpreting the material that resulted from the workshop was far from linear. I sent the first invitations before properly planning the set-up of the workshop, and the processes of conducting workshops and scheduling subsequent workshops ran parallel. Even the interpretation can be described as synchronous with the other parts of work, because themes and question emerging in one workshop inevitably shaped what I was looking for in the next. For clarity, however, I have organized the process in three parts: planning, conducting, and interpreting.

\section{Mapping the Field and Finding Student Participants}

In the preparatory stages of the project I had been in contact with two universities in Sweden and two in Estonia, where I wanted to locate the workshops to make participation easy for students. Keeping in mind that participants can opt out with short notice, I aimed for two group of six students at each university. To invite students to participate, I asked the teacher educators I had previously been in contact with for permission to conduct the workshops at their institution and for advice on the setting.

Being located in Sweden, I decided to start inviting students at one of the universities there. My contact there agreed to lend me a room for the workshop and advised me to offer the students some kind of gift for participating, such as cinema tickets. While following her advice, I sent out two reminders before I had one group of four students interested in participating. Of those, only two showed up for the actual workshop.

After this, I was unsure if it was realistic to perform the workshops as planned, but I made the same query to a teacher educator at one of the Estonian universities (which has a joint art teacher program together with the other Estonian university). In this case, I was less flexible with dates and asked for help to schedule two workshops during the same week. My contact scheduled the workshops within the course timetables, and I obtained six student participants for the first workshop and two for the second.

Back in Sweden, a teacher at the university where I conducted the first workshop invited me to integrate the workshops as part of his course. Because his course was mandatory, the 
student had to participate, but in order to use the material from these workshops in my research I had to get their permission in advance. After visiting the class and introducing the project, a group of six students agreed to participate in the project. I and the other teacher then split up the

group and conducted the workshops in separate rooms; this allowed me to record the discussions in my group, as all those in this group agreed to being recorded.

The final two workshops were conducted in a university where I teach, which made it possible for me to introduce the project and invite students during the course of my lecture. This was by far the most efficient way to recruit participants. I conducted two workshops with five students each, separate from the courses they took. Prior to these two workshops, the students and I had as discussion about power relations in the group, related to my double role as a researcher and their former lecturer.

In all the workshops, the students were offered some food, drinks, and/or snacks. Apart from the first interview in which I, on the advice of my teacher contact, offered participants cinema tickets, no other reimbursements were handed out. This means that to recruit students to participate in the workshop, I was dependent on their kindness and interest, as well as on the good will of the teacher educators who provided access to the students. Such mutual confidence is dependent not only on common interests, but also on sympathy and trust. In the university where I teach, I had already built up a capital of trust, but in the other cases, getting in contact with student participants and facilitating a safe and friendly environment for discussion demanded a fair amount of emotional labor, the task of managing my own and others feelings (Hochschild, 1983). As noted by Sonia Livingstone (2003), this applies especially in crossnational research, where differences in etiquette and conventions must be handled by the researcher.

\section{Conducting the Workshops}

In total, I conducted six workshops - two in Estonia and four in Sweden. They all followed the same structure and were documented through audio recording and still images. Each session was about two hours long, and followed three steps: A preparation phase where I introduced myself and the aim of the project, and the participants introduced themselves, a critique phase mapping 
their current experience of media technologies in art education, and last, a fantasy phase where the participants visualized an imaginary future art classroom. These steps are inspired by the phases described by Jungk and Müllert (1987) in the Future workshop framework, alongside a fourth and fifth step, namely the implementation phase and the follow-up phase. In the original approach, these steps were contained the concrete plans for implementing and controlling the vision developed in the third step, but have been excluded from this research design because the aim of the project is theoretical understanding rather than actual hands-on development of education.

\section{Preparation Phase}

After presenting myself, the project and how the material was going to be used, the participants introduced themselves and their interest in the project. This was followed by a discussion about terminology, whereby we tried to agree on a common understanding of media infrastructure that included also software, platforms, obsolete technologies, and soft infrastructure, like curricula and grading.

\section{Critique Phase}

After this, I asked the participants to first, draw all the media technologies in the room we were located in; second, to draw all the media technologies they have encountered throughout their teacher training; and third, to draw the media technologies they have met or used during their school practice period, including both visible in-class technologies such as a LED projector or a printing press, and "invisible" technologies such as Internet access. This mapping was facilitated through discussions in the group - helping the participants to remember and to agree among each other who should draw what. I also participated in the discussion and encouraged the discussion with questions and suggestions. The images produced by the participants were then cut out and placed on a large board (Figure 1).

\section{Figure 1.}

Caption: Cutouts of art teaching media technologies from the critique phase.

\section{Fantasy Phase}

In the last phase, I asked the participating students to use the images from the mapping, and to make new ones, to create their desired future art classroom on the board (Figure 2). The 
classroom should facilitate the kind of art education they assumed would be needed in the future and thus visualize social imaginaries about the subject itself, and its role in society. I encouraged the participants to discuss among themselves about what to include, what to get rid of, and what to add - and to organize this into a common mental map that included both physical and virtual space.

\section{Figure 2.}

Caption: Participants in the process of creating a common map of the future art classroom.

This final image was not the goal of the workshops; rather, it was a way to encourage infrastructure literacy and provoke a discussion about future imaginaries in the group. This has two implications: first, the final image should not be considered a finished result, but a process in the stage where we left it and second, the recorded audio and the process photographs become as important as the final image or map and must be interpreted together.

\section{Interpreting the Material}

The interpretation process was performed by listening to the audio and looking at the image material together. The process photographs were very important in understanding what technologies were opted out of future education, as well as how different technologies were categorized and re-categorized during the process. In some groups, it was also possible to follow the negotiation process visually because the participants moved the cut-outs around a lot, whereas other groups engaged in discussion before rearranging the cut-outs on the board.

That I was able to track some processes by aligning the audio with the images does not mean that the images serve as an illustration to the audio, or that the interpretation process was linear. Indeed, some of the more interesting connections were made from combining different parts of the material; for example, in one workshop, a participant started off by being a bit annoyed and saying, "I thought we were going to talk about classrooms and I came here to say that I really don't like these new classrooms with glass walls!” and then, much later in the process, the visual material showed that the same participant, when working with the group to 
create their map of a future art classroom, tried to get rid of the cut-out representing a learning platform (but was overruled by the rest of the group).

This connection made me notice the themes of transparency, surveillance, and control as social imaginaries surrounding digital technology, themes that could inform further interpretation of the material. Another imaginary made visible in the mapping is convergence. In several of the workshops, participants put different technologies in a pile, behind a computer cut-out, or in other ways to indicate that in the future, one device could contain the functions of many present technologies.

\section{Practical Lessons Learned}

As described in the previous section, the task of finding participants proved to be very time consuming and demanding. Considering that I have not experienced the same difficulties when asking teacher educators or others for semi-structured interviews, this might have to do with the workshop format and the fact that the participants did not know what to expect from the situation. This is one of the challenges of using innovative or creative methodologies, but may be partly solved by emotional labor and pedagogic skills, described in the following subsection: Experiences from teaching - ritual aspect of setting up a workshop. I then discuss the limits and benefits of implementing such methodologies in different national contexts in the section $A n$ outsider's access to the mundane, followed by the last section, Now see it - then what?, on how the workshop method can be complemented with other approaches.

\section{Experiences From Teaching-Ritual Aspect of Setting Up a Workshop}

As previously described, building trust with the participants and helping them feel comfortable in the situation can be defined as a kind of emotional labor. In this work, I used experiences from teaching, framing the workshop as an event or ritual. In order for the participants to feel that something special and important was going to happen, I put some effort in setting up the space of the workshop. I set out the material needed, such as pens, papers, and scissors, neatly on the table. On another table, I arranged the food nicely on a table cloth (Figures 3 and 4). Preparing 
the room also means managing my own emotions and trying to feel at home and in control of the situation. The rigid dramaturgy of the workshop was also inspired from (art) teaching, whereby the area of inquiry and/or the material resources are determined, but not the knowledge outcome. This design worked well to create a sense of ritual, well-planned event.

\section{Figure 3.}

Caption: Preparing food and snacks as emotional labour put into the set-up of the workshop.

\section{Figure 4 .}

Caption: Workshop materials arranged in such a way as to create a sense of ritual and care.

\section{An Outsider's Access to the Mundane}

Another methodological difficulty is that the workshops are conducted in different national contexts. With a background in Swedish art education, the amount of contextualizing research needed there before performing the workshops differs from that needed in Estonia, where I had to do extensive fieldwork before even getting in contact with the art teacher educators or understand what to ask them. In this case, as in most qualitative research, this means that methodological standardization was neither possible nor desired. Also in the workshops, I had to ask a lot of clarifying questions to compensate for my lack of knowledge about the Estonian school system. Paradoxically, an explanation of everything from the national system of extracurricular art schools to the habit of making children bring their own art supplies to school became a kind of "infrastructural inversion", and the obstacle of being an outsider turned to an advantage. A practical lesion is therefore to try to assume some kind of outsider position to have the participants make the familiar visible.

\section{Now See It-Then What?}

Using mapping as a method also brings forth questions about visualization in relation to interpretation. In the workshops, the participants visualized the infrastructures and social imaginaries that guide art education — now what? Mere mapping is not enough, or as put by infrastructural researcher, Shannon Mattern (2013: n.p.): 
The ambitious intentions to "make visible the invisible" and raise awareness of imperceptible systems, much like Situationist-style dérives or interventions, can too often become ends in themselves.

What is needed is not just awareness of existing infrastructures but also the ability to imagine potential ones and to act upon these ideas. This leads to my final point where I want to emphasize that this method was part of a mixed methodological approach. My experiences suggest that creative workshops alone are an insufficient way to study infrastructure. First, they lack a necessary historical perspective to track how infrastructures build upon each other. Second, a workshop approach works well to study how infrastructures are imagined, negotiated, and maintained, but not so much how infrastructures are constructed. To include these aspects in a research project, the workshop method must be combined with other approaches such as interviews and site visits.

\section{Conclusions}

In this text, I have discussed creative workshops as a way to research invisible, or at least opaque, structures guiding everyday life, work, and culture: media infrastructures and the social imaginaries surrounding those. The benefits of such an approach are the possibilities of facilitating participation and discussion among the participants by "getting things on the table," and by making abstract questions about future projections more concrete. In order for this to work, the researcher must be able to manage his or her emotions, as well as to make the participants feel comfortable.

I have described the process of planning, conducing, and interpreting the workshops as messy and non-linear, and the same applies to the research process where research questions, theoretical concepts, experiences, and methods were developed simultaneously and in relation to each other. When I first started the research process, I received advice to let the theoretical frame guide the methodological approach. It is good advice, but the theoretical frame must have some resonance in the study, and to gain access to that field, you have to start with some kind of approach. In this way, some aspects of the research process means going in blind and staying open for that which does not work. 


\section{Exercises and Discussion Questions}

1. The case study examines the intersecting infrastructures of a specific school subject. Think about your own university studies and

(a) Identify the infrastructures that underlie them.

(b) Discuss approaches of studying these infrastructures.

2. In the case described here, some of the limits and possibilities of creative workshops is discussed.

(a) Identify other benefits of the Future workshops method in this case study.

(b) Identify other limits of the Future workshops method in this case study.

3. Develop your own workshop setup to fit a chosen field of study, preferably something you have or are about to research. Be as concrete as possible and consider which participants and how many participants you would want to invite, how you will get in contact and recruit these participants, the structure of your workshops as well as the modes of documentation and approaches for interpretation.

\section{Further Reading}

Edwards, P. N., Bowker, G. C., Jackson, S. J., \& Williams, R. (2009). Introduction: An agenda for infrastructure studies. Journal of the Association for Information Systems, 10, 6.

Jackson, S. J., Edwards, P. N., Bowker, G. C., \& Knobel, C. P. (2007). Understanding infrastructure: History, heuristics and cyberinfrastructure policy. First Monday, 12(6). http://www.firstmonday.org/ojs/index.php/fm/article/view/1904/1786 (accessed 28 September 2017).

Lauttamäki, V. (2014). Practical guide for facilitating a futures workshop. Finland Futures Research Centre, Turku School of Economics. Retrieved from www.utu.fi/fi/yksikot/ffrc/kehittamispalvelut/futuresfocus/Documents/futuresworkshops.pdf (accessed 2 April 2015). 
Selwyn, N. (2010). Looking beyond learning: Notes towards the critical study of educational technology. Journal of Computer Assisted Learning, 26, 65-73.

Star, S. L. (1995). Ecologies of knowledge: Work and politics in science and technology. Albany: State University of New York Press.

Vavoula, G. N., \& Sharples, M. (2007). Future technology workshop: A collaborative method for the design of new learning technologies and activities. International Journal of ComputerSupported Collaborative Learning, 2, 393-419.

\section{Web Resources}

The Sociotechnical Imaginaries Project:

http://sts.hks.harvard.edu/research/platforms/imaginaries/ (accessed 12 May 2017).

\section{References}

Bowker, G. C., \& Star, S. L. (1999). Sorting things out: Classification and its consequences. Cambridge, MA: MIT Press.

Gauntlett, D. (2007). Creative explorations: New approaches to identities and audiences. London, England: Routledge.

Hochschild, A. R. (1983). The managed heart: Commercialization of human feeling. Berkeley: University of California Press.

Jasanoff, S., \& Kim, S.-H. (2009). Containing the atom: Sociotechnical imaginaries and nuclear power in the United States and South Korea. Minerva, 47, 119. doi:10.1007/s11024-0099124-4

Jungk, R., \& Müllert, N. (1987). Future workshops: How to create desirable futures. London, England: Institute for Social Inventions. 
Livingstone, S. (2003). On the challenges of cross-national comparative media research.

European Journal of Communication, 18, 477-500.

Lynch, K. (1960). The image of the city. Cambridge, MA: MIT Press.

Mattern, S. (2013). Infrastructural tourism. Places Journal. Retrieved from https://placesjournal.org/article/infrastructural-tourism/ (accessed 21 April 2017).

Parks, L. (2009). Around the antenna tree: The politics of infrastructural visibility. Flow, 8. Retrieved from https://www.flowjournal.org/2010/03/flow-favorites-around-the-antennatree-the-politics-of-infrastructural-visibilitylisa-parks-uc-santa-barbara/ (accessed 21 April 2017).

Parks, L. (2015). "Stuff you can kick": Toward a theory of media infrastructures. In P. Svensson \& D. T. Goldberg (Eds.), Between humanities and the digital (pp. 355-373). Cambridge, MA: MIT Press.

Parks, L., \& Starosielski, N. (2015). Signal traffic: Critical studies of media infrastructures. Champaign: University of Illinois Press.

Star, S. L., \& Ruhleder, K. (1996). Steps toward an ecology of infrastructure: Design and access for large information spaces. Information Systems Research, 7, 111-134. 